\section{Stimulus variables in single-letter recognition*}

\author{
A. O. DICK $†$ \\ University of Rochester, Rochester, N.Y. 14627
}

The present experiment examined the role of some stimulus variables in determining single-letter recognition. The twenty-six letters of the alphabet were presented individually with systematic manipulations of size and exposure duration. The results show that recognition accuracy is a function of both size and exposure duration; these data imply that present conceptions of feature analysis are somewhat incomplete.

Several experiments carried out in our laboratory have shown inconsistent effects when single letters are used as stimuli. In some cases, the relation of recognition accuracy and frequency of usage varies from being a significant correlation to an insignificant one. Furthermore, phenomenal report of the items is equally inconsistent; under certain conditions, only part of the letter is seen which produces low accuracy, although under other conditions the same letter shows a high level of accuracy. These various preliminary findings are in contrast to effects reported for multiple displays (e.g., Howes \& Solomon, 1951; Sales \& Haber, 1968). One possibility for the discrepancy between single- and multiple-letter presentations is that contextual information plays a crucial role in multiple presentations. Single-letter presentations lack contextual information and therefore accuracy is much more likely to be governed by stimulus parameters. The present experiment is a demonstration that stimulus parameters, such as exposure duration, play an important role in determining accuracy of letters presented individually.

\section{STIMULI}

Three sets of stimulus cards were prepared by placing Deca Dry letters (Styles 2712, 2724, 2736) individually on white cards. These letter styles represent three different sizes of letters; when viewed in the tachistoscope, the visual angles were approximately $0.14, \quad 0.29, \quad 0.43 \mathrm{deg}$, respectively. In addition, a set of practice cards consisting of numbers was prepared using the same type style.

PROCEDURE

The stimuli were shown individually in Field 1 of a Scientific Prototype Model G tachistoscope. The items were presented one at a time just above a small black fixation point that was visible at all times

*This research was supported by National Science Foundation Grants GB 7848 and GB 17138. The assistance of Thomas Barnes for collection of the data is gratefully acknowledged.

$\dagger$ Present address: University of Rochester,

Department of Psychology, River Campus Station, Rochester, N.Y. 14627. except when the letter was being exposed. Each $\mathrm{S}$ was given a series of practice trials on numbers at an exposure duration of $11 \mathrm{msec}$. During this practice exposure, the luminance was manipulated such that accuracy was about $90 \%$. When performance was stable in practice, the experimental trials began. The $\mathrm{S}$ was shown one of the sizes five times, once at each exposure duration of $11,9,7,5$, and $3 \mathrm{msec}$. All Ss were tested with descending exposure durations. Several different orders of presentation were used to minimize learning of the sequence.

\section{SUBJECTS}

The Ss were 30 undergraduate students taking an introductory course in psychology; participation fulfilled part of the course requirement.

\section{RESULTS AND DISCUSSION}

Correct responses for each trial were entered into an analysis of variance [Ss by Groups (size) by Duration by Letters] Significant effects were attributed to exposure duration $(\mathrm{p}<.001)$ and letters $(\mathrm{p}<.001)$ and to the interactions of Exposure Duration by Size $(\mathrm{p}<.001)$ and Exposure Duration by Letters $(p<.01)$. None of the other effects were significant.

The effect of exposure duration is to be expected; accuracy decreased in a monotonic manner as exposure duration decreased. The failure to obtain overall differences due to size was also expected because this was part of the design; the manipulated so that accuracy would be equivalent for all sizes at the $11-\mathrm{msec}$ duration. That $\mathrm{F}=0.56(\mathrm{df}=2,27)$ for the main effect of size indicates that the manipulation of luminance was reasonably good in equating the accuracy for three sizes.

The effects of major interest in the experiment were those involving stimulus parameters. Both the interactions of Exposure Duration by Letters and Exposure Duration by Size were significant. These results are consistent with findings reported by Bryden (1968). He reported that asymmetrical letters are more accurately identified than intensity of the exposure field was symmetrical letters when presented individually, but asymmetrical letters are less accurately identified than symmetrical letters in the context of other letters. Whether these differences can be explained in terms of contextual information or in terms of confounding stimulus parameters cannot be determined from the present data. Although most investigators employing linguistic visual stimuli have not carefully examined and controlled stimulus factors, the present data do suggest that variables of duration and intensity should receive more attention.

These results are not consistent with feature analysis theory (e.g., Neisser, 1967). Neisser has suggested that features such as concavity and angularity are extracted from stimuli. It is implied that some underlying neural structure is involved and, more importantly, that this structure is arranged hierarchically. Such an assumption implies further that the relation of feature processors is fixed. However, the relation within single-letter recognition varies as a function of stimulus parameters, and therefore it seems that Neisser's notion of feature extraction is incomplete.

The necessary extension seems to require the addition of inhibitory processes (e.g., von Békésy, 1967). Inhibition seems necessary to sharpen contour. Available evidence suggests that the inhibitory system operates somewhat differently than the excitatory system, that the receptive field organization in cat changes as a function of the adaptation state (Barlow, Fitshugh, \& Kuffler, 1957). It may also be reasonable to expect differences in time constants for excitatory and inhibitory systems. If it takes longer to activate inhibitory mechanisms than it does to activate excitatory mechanisms, the present results can be explained. The longer the stimulus exposure, the more opportunity for inhibition to occur. A change in inhibitory activity relative to excitatory activity would be sufficient to alter the relative accuracy of a letter. The present interpretation is highly speculative but does explain the present results and can be tested experimentally.

\section{REFERENCES}

BARLOW, H. B., FITZHUGH, R., \& KUFFLER, $S$. W. Change of organization in the receptive tjelds of the cat's retina during dark adaptation. Journal of Physiology, 1957, 137, 338-354.

BRYDEN, M. P. Symmetry of letters as a factor in tachistoscopic recognition. American Journal of Psychology, 1968, 81, 513-524.

HOWES, D. H., \& SOLOMON, R. L. Visual duration threshold as a function of word-probability. Journal of Experimental Piychology, 1951, 41. 401-410.

NIEISSER. U. Cogritive psychology. New York: Appleton-Century-Crofts. 1967. 
SALES, B. D., \& HABER, R. N. A different look at perceptual defense for taboo words. Perception \& Psychophysics, 1968, 3.

156-160.

von BEKÉSY, G. Sensory inhibition. Princeton. N.J: Princeton University Press, 1967.

\title{
Progressive decay of the memory trace
}

\author{
D. McNICOL \\ University of Adelaide, Adelaide, Australia
}

The effects of delay on recall of material in short-term memory were studied by presenting a sequence of items and requiring ordered recall either immediately after presentation or after $1 \frac{1 / 2}{\mathrm{~min}}$. Although the total number of errors made did not increase significantly as a result of delay, errors concerned with the ordering of the items were evident even when the material was recalled immediately, but these were replaced by errors concerned with the selection of items themselves when recall was delayed.

Short-term memory is often investigated by presenting a list of items just once and asking for recall shortly afterwards. It has been customary to require the items to be reproduced in correct order, and when a $S$ attempts to do this he is prone to two types of error. First, items are recalled that did not appear in the original message (intrusion errors), and second, correct items may be given in the wrong order (transposition errors). This distinction was first made by Bolton (1892), who also remarked that the two types of error appeared to occur at different stages of memory. "Memory images pass through three stages in leaving the mind. First, they suffer a confusion of order; second, a loss of certain elements and the substitution of associated elements; and third, a complete loss of some elements and no recovery [Bolton, p. 380]."

The decay of the trace representing the items in a verbal message has been investigated by Conrad (1967), who varied the interval between the presentation of four consonants and their recall. When the delay between presentation and recall was $2.4 \mathrm{sec}$, intrusion errors tended to be items acoustically similar to those they replaced (e.g., B may have been replaced by V, M by $\mathrm{N}$ etc.). With a delay of $7.2 \mathrm{sec}$, intrusions were less strongly acoustically related to the items for which they were substituted but tended to be more random. Thus, as Bolton suggested, certain elements are lost as the trace decays, and, for verbal material, these appear to be of an acoustic nature.

Less is known about the decay of the trace representing the temporal order of items in a message. Brown (1959), like Bolton, has suggested that information about order decays rapidly. His model, based on information theory, states that memory traces are coded with varying amounts of redundancy, traces for order being less redundant than those representing the items. Even after considerable decay, a highly redundant item trace may preserve sufficient information to guarantee a correct response, but order traces, not being well protected in this way, may have insufficient information in them to prevent transpositions after even short retention intervals. On this view there should be a change in the type of error made at different retention intervals, transpositions being dominant soon after hearing a message showing a rapid loss of order information and their place being taken later by intrusions as item information is lost.

Twenty Ss, all undergraduates from Cambridge University, heard the same tape-recorded message of eight words, spoken at the rate of one word/second. The words were: MAP, ARM, CUP, BAG, SAW, KEY, EGG, PAN, and OAK. All came from Thorndike \& Lorge's (1944) A or AA frequency lists. Ss were told to remember the words in correct order. Ten Ss served in the first recall condition, in which they were told immediately after Table 1

The Mean Number of Intrusions and Transpositions Made in Recall of the 8-Item List Immediately After Presentation or After a 11/2-Min Delay

\begin{tabular}{|c|c|c|c|}
\hline & $\begin{array}{l}\text { mmediate } \\
\text { Recall }\end{array}$ & $\begin{array}{l}\text { 11/2-Min } \\
\text { Delay }\end{array}$ & $\begin{array}{l}\text { Mean } \\
\text { Total }\end{array}$ \\
\hline Intrusions & 3.2 & 5.0 & 4.1 \\
\hline Transpositions & 3.3 & 2.0 & 2.7 \\
\hline Total & 6.5 & 7.0 & \\
\hline
\end{tabular}

presentation to write down the eight words, guessing any items that they had forgotten. The other 10 Ss served in the second recall condition in which recall was delayed for $1 \frac{1}{2} \mathrm{~min}$, during which time they received instructions for another experiment. They were then required to write down the words in correct order, guessing forgotten items.

RESULTS AND DISCUSSION

The results are presented in Table 1. It can be seen that while there is little increase in the total number of errors made as the retention interval is increased from immediate recall to $1 \frac{1 / 2}{2}$ min delay, a greater proportion of the immediate recall group's errors are confusions of order. An analysis of variance for a split-plot design was performed. The overall effects of delay were insignificant, but the $F$ for error type was significant $(F=9.14, d f=1 / 18$, $\mathrm{p}<.01)$. This appears due to the interaction between error type and delay $(F=10.45, \quad d f=1 / 18, \quad p<0.01)$, which shows a significant tendency for the number of transpositions to decrease from immediate recall to $1 \frac{1}{2}$ min delay.

The result of this experiment is therefore compatible with the views of Bolton and Brown, that the short-term trace is most susceptible to loss of information about the ordering of items. Immediately after presentation, recall of items is accurate, but already memory for their positions is poor. After a delay, memory for the items themselves has worsened and intrusions are the dominant type of error. Since the conducting of this study, Murdock \& vom Saal (1967) have published data that supplements this finding. Their Ss recalled three-word messages after delays of 3, 9, and $18 \mathrm{sec}$. It was found that as the retention interval increased so did the number of transposition errors. Thus it seems that the memory traces for items and their temporal order decay over time, but that those for the latter deteriorate more rapidly.

\section{REFERENCES}

BOL TON, T. H. The growth of memory in school children. American Journal of Psychology, $1892,4,362-380$.

BROWN, J. Information, redundancy and decay of the memory trace. In: Mechanisation of thought processes. National Physical Laboratory Symposium No.10. Vol. 2. London: Her Majesty's Stationary Office. 1959. Pp. 729-752.

CONRAD, R. Interference or decay over short retention intervals. Journal of Verbal Learning \& Verbal Behavior, 1967,6, 49-54.

MURDOCH, B. B., JR.. \& vom SAAL, W. Transpositions in short-term memory. Journal of Experimental Psychology, 1967, 74. 137-143.

THORNDIKE, F. L., \& LORGE, J. The teacher's word book of 30.000 nords. New York: Bureau of Publications, Teachers College. Columbia L'niversity, 1944. 